\title{
Geology from home
}

\section{Many geologists are used to spending at least part of their working lives in the outdoors - but all that changed in March. Clive Mitchell from the British Geological Survey shares his experience of working from home during the current Coronavirus (COVID-19) outbreak}

M y current extended home working experience started on Wednesday 18th March 2020, along with a lot of my colleagues from the British Geological Survey (BGS). I work at the BGS headquarters in Keyworth, located just south of Nottingham, mostly on minerals related projects. My current work includes graphite resources in eastern Africa, Artisanal \& Smallscale Gold Mining (ASGM) in Kenya (both part of the BGS Official Development Assistance, ODA, research programme) and, closer to home, a new version of the BGS Mineral Planning Factsheet on Brick Clay.

My home is in Gedling to the east of Nottingham city centre. My daily commute has shrunken from 30 minutes down to 10 seconds (up the stairs and turn left into the spare room).

Instinct told me a couple of days before it happened that homeworking was imminent. I literally filled a box with rocks and stuck it in the boot of the car with my mini-microscope and plenty of minerals books. I'm glad I did - later the same day the home working request was announced nationally. I went into the office the next morning to gather my essentials together - I have a laptop with a docking station that allows me to connect a monitor and keyboard. I'm so glad I bought this home with me!

I set up my new office, in what I'm calling the Gedling branch of the BGS, on the first morning of home working and I pretty much hit the ground running. I think this was mainly fuelled by an initial burst of energy. ('Even more energy?!' my BGS colleagues will think!) I have calmed down a little since then.

After day six of working from home, here are some of my tips for home working that might help if like me, you are adapting to new challenges and rapid changes:

\section{Try to keep work \& home apart}

I've been sticking to my usual office hours, but with a much longer lunch break. I'm lucky to have a spare room to work in, which means I can close the door on work until the next day. I usually put on a work shirt too - old school, maybe, but it makes me feel as though l'm at work. And when I return (get to the bottom of the stairs) I always say 'I'm home!' It's the little things like this that I feel will keep me sane.

\section{Stay in touch}

It's tempting to go into work isolation mode but l've found that my day improves when I'm in contact with people. I appreciate it when people share their experience of the current situation, no matter how fleeting. The BGS has been using Zoom for video meetings. For example, this morning the BGS minerals team had a virtual coffee time using Zoom and it lifted my spirits immeasurably.

Don't overdo it! People often comment on how much extra they get done when they work at home - fewer interruptions mean more focus. I would normally only work from home on very rare occasions, typically when I need to focus on writing. This is fine for a day or so. However, as it's a more concentrated form of working I figure that I need to pace myself for the long haul.

\section{Get some exercise}

I do exercise regularly. However I think the point is that it is not just the physical exertion that is important. It's the change of scenery, the fresh air and sunshine too. My colleagues at BGS in Keyworth will smile at this - sunshine can be rare in the East Midlands! Each day at lunchtime I take a long walk (before I get collared for jobs around the house!) and l've really noticed a difference afterwards. As geologists, the outside is for many of us our natural habitat - if you're lucky you might see a few rocks on the way, too.

I hope that you are faring well and that if you are working from home it's a good experience. Hopefully we can all take some positives from this experience back to the workplace. Connecting more with people is one lesson l've already learnt.

Clive Mitchell is Industrial Minerals Geologist at the British Geological Survey. Follow Clive on Twitter via @CliveBGS to keep track of how he is getting on working from home.
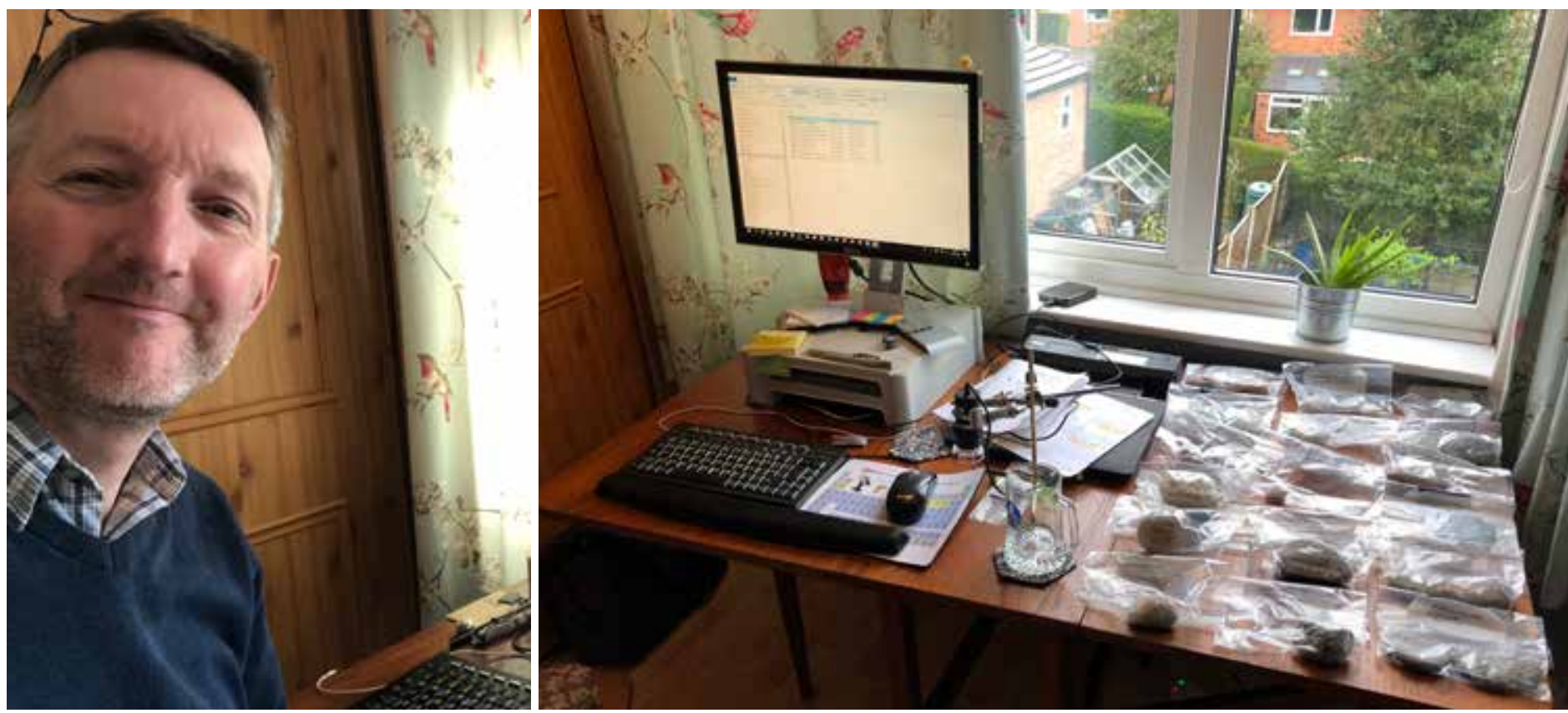